Parent-Implemented Oral Vocabulary Intervention for Young Children with Down Syndrome Lauren M. LeJeune ${ }^{1}$, Christopher J. Lemons ${ }^{2}$, Silje Hokstad $^{3}$, Rebeca Aldama ${ }^{4}$,

\author{
and Kari-Anne B. Næss ${ }^{3}$ \\ ${ }^{1}$ University of South Carolina \\ ${ }^{2}$ Stanford University \\ ${ }^{3}$ University of Oslo \\ ${ }^{4}$ University of Québec at Montréal
}

\begin{abstract}
Author Note
This is an early version of the paper (before it was accepted).
\end{abstract}

Lauren M. LeJeune, Department of Educational Studies, University of South Carolina; Christopher J. Lemons, Graduate School of Education, Stanford University; Silje Hokstad, Department of Special Needs Education, University of Oslo; Rebeca Aldama, University of Québec at Montréal; Kari-Anne B. Næss, Department of Special Needs Education, University of Oslo.

This research was supported in part by a Vanderbilt University Discovery Grant, the Office of Special Education Programs within the U.S. Department of Education (Grant H325D140073), the Research Council of Norway’s Finnut program (Grant 238030), and internationalization support from University of Oslo (UIO): Life Science. Nothing in the article necessarily reflects the positions or policies of the funding agencies and no official endorsement by them should be inferred. The DSL+-teaching materials described in this paper were originally developed in Norwegian and were translated and adapted by this research team. We thank the 
EngageLab (Faculty of Educational Sciences, UiO) for their technical adaption of the DSL+ application.

Correspondence concerning this article should be addressed to Lauren M. LeJeune, Department of Educational Studies, University of South Carolina, Columbia, SC 29201. Email: llejeune@mailbox.sc.edu 


\begin{abstract}
Young children with Down syndrome (DS) often demonstrate impaired oral vocabulary development; however, few intervention studies have focused on this population. One promising method to improve the oral vocabulary of young children with DS may be to train their parents to intervene at home. In this study, we used tele-education methods (e.g., video conferences, email) to coach parents to implement an adapted version of the Down Syndrome LanguagePlus intervention (DSL+; Næss et al., in progress). Four children with DS (ages 5 to 6 years) participated in the multiple probe across behaviors (i.e., stories) single case research design study. Results indicated that all participants increased their scores on mastery measures of targeted vocabulary; however, increasing trends during baseline and data variability precluded confirmation of a functional relation. Three of four parents implemented DSL+ with high fidelity and responded favorably to social validity interviews. Limitations, suggestions for future research, and implications for practice are discussed.
\end{abstract}

Keywords: Down syndrome; language; vocabulary; early intervention; parent training 


\section{Parent-Implemented Oral Vocabulary Intervention for Children with Down Syndrome}

Down syndrome (DS) is a chromosomal condition that occurs in about 1 in every 830 live births per year in the United States (Parker et al., 2010) and is the most common genetic cause of intellectual disability (Fidler \& Nadel, 2007). Children with DS often experience delays or differences in their development of oral vocabulary (i.e., ability to use words in speech and recognize words while listening). DS characteristics that include impaired hearing (Nightengale et al., 2017), difficulties holding verbal information in working memory (Jarrold \& Baddeley, 2001), and differences in mouth structure and muscle tone that affect speech production (Abbeduto et al., 2007) may contribute to this language profile. Environmental factors may also contribute; for example, poor speech production may result in adults misunderstanding speech and failing to reinforce new words or ask complex questions (Abbeduto et al., 2007; Jordan et al., 2011). It appears, however, that individuals with DS can learn new words through multiple exposures and opportunities to use targeted words in context (Chapman et al., 2006). Parents should be included in vocabulary intervention efforts, given the strong link between young children's language interactions with their parents and later vocabulary and literacy skills (O’Toole et al., 2018). However, there is currently limited research on designing vocabulary interventions to meet the needs of children with DS and their families (Jordan et al., 2011).

\section{Oral Vocabulary Intervention for Children with DS}

A robust body of research indicates that early intervention can increase oral vocabulary skills of children without disabilities (see reviews by Flack et al., 2010; Marulis \& Neuman, 2018), and a growing number of studies have included children with or at-risk for disabilities (see reviews by Heidlage et al., 2019; Roberts \& Kaiser, 2011; Swanson et al., 2011). Across these five reviews, results indicate that effective interventions include explicitly teaching word 
meanings (i.e., direct instruction), implicitly teaching words within the context of activities (e.g., incidental teaching), shared book reading, dialogic reading techniques (e.g., describing pictures, asking questions), story repetitions, and the use of words in multiple contexts. However, there is limited evidence to support the effectiveness of these procedures for children with DS.

To our knowledge, two research groups (O’Toole et al., 2018; Smith et al., 2020) have conducted systematic reviews broadly focused on language intervention for young children with DS. O'Toole et al. (2018) identified three studies that involved training parents to implement intervention (two randomized control trials [RCTs], one quasi-RCT) and included 45 total participants (ages 29 months to 6 years old). All interventions were multi-component packages (e.g., enhanced milieu teaching) that each included research-supported components (e.g., incidental teaching, direct instruction). Only one study reported significant effects on general measures of children's language ability; however, two studies found that children in the intervention group used significantly more of the targeted words at post intervention. O'Toole et al. (2018) rated the overall quality of the evidence as very low due to the small sample sizes and high risk of bias (e.g., lack of blinding).

Smith et al. (2020) identified eight language intervention studies with control group designs that included 108 children in the intervention groups and 103 children in the control groups (ages 5 to 10 years old). There was large variability in intervention characteristics (e.g. language components targeted, dosage of intervention), and only three of the eight studies focused on vocabulary skills. There was a large mean effect $(g=1.01 ; \mathrm{CI}=-0.54,2.57)$; however, one study positively skewed the mean (Baxter et al., 2018). Smith et al. concluded that there remains a need for more high-quality studies to inform effective vocabulary intervention for young children with DS. 


\section{Training Parents to Implement Oral Vocabulary Intervention}

The negative impact of early vocabulary deficits on children's future literacy skills (e.g., decoding and comprehension) points to the necessity of early intervention (Skibbe et al., 2008). Such intervention should occur in the natural home environment, considering that parents (or other primary caregivers) are typically a young child's first communication partners and the link between parent interactions and child language development has been well-established (Heidlage et al., 2019; O’Toole et al., 2018). Furthermore, parents of children with impaired vocabulary development (such as some children with DS) may not naturally engage in high-quality interactions, and thus, benefit from training and support (Roberts \& Kaiser, 2011).

Parent-implemented language and vocabulary interventions have shown some promise for children at-risk for disabilities (Heidlage et al., 2019; Roberts \& Kaiser, 2011) and children with DS (O’Toole et al., 2018). However, methods for effectively training parents are unclear. For example, Roberts and Kaiser (2011) identified 18 studies focused on parent-implemented language interventions, yet 13 omitted parent fidelity data and 9 lacked descriptions of training procedures. Heidlage et al. (2019) identified a similar lack of training descriptions, and O’Toole et al. (2018) did not report specific training information. Thus, there is a need to identify methods that best accomplish parent training and to identify relations between training methods, training dosage, and levels of intervention fidelity.

Practitioners of applied behavior analysis (ABA) commonly use one adult training model that may be applicable. Behavioral skills training (BST; Parsons et al., 2012) is an ABA-based method with a strong body of research supporting its effectiveness in training a variety of adult learners (e.g., teachers, human service staff, parents; Kirkpatrick et al., 2019). BST models typically include four primary components: (1) instruction, (2) modeling, (3) rehearsal, and (4) 
feedback. BST is often performed one-on-one or in small groups in the natural context in which the trainee would perform the skill (e.g., home, school). BST procedures can be adapted to meet trainee needs; for example, trainers may use video models if in-vivo training time is limited (Kirkpatrick et al., 2019). The use of technology may be advantageous for families who implement intervention during times that a trainer is unlikely to attend in person (e.g., evenings, weekends). Emerging evidence indicates that BST can be effectively delivered in tele-education formats with teacher participants (e.g., Higbee et al., 2016). Similar methods may be effective for training parents of children with DS to implement oral vocabulary intervention.

\section{The Down Syndrome LanguagePlus Intervention}

Recently, Næss et al., (in progress) responded to the lack of research on oral vocabulary intervention for children with DS by developing a systematic intervention package-The Down Syndrome LanguagePlus (DSL+). Multiple research-supported components (e.g., picture book dialogues, direct instruction, story repetition, the use of words in different contexts) are included in the DSL+ intervention. Children receive the vocabulary intervention from an educator for five days per week across 30 weeks. The developers selected targeted vocabulary based on: (a) age of acquisition (Kuperman et al., 2012), (b) frequency of exposure (Van Heuven et al., 2014), (c) relevance to social relationships, and (d) inclusion within common school curricula. DSL+ includes several visual and auditory representations of the targeted vocabulary with the aim of developing both breadth and depth of word knowledge. Instruction follows a reoccurring task structure designed to meet the learning needs of children with DS and to promote implementation fidelity. Most of the tasks are delivered through an iPad® application (app), with accompanying supplementary materials (e.g., picture cards and toys) for practical activities. 
To date, Næss et al. (in progress) have completed one RCT to investigate whether DSL+ increased oral vocabulary usage for children with DS. Participants were a national cohort of 103 Norwegian $1^{\text {st }}$ graders with DS (ages 5 to 7 years old). Analysis of the data is ongoing, but preliminary analysis of qualitative data indicated that educators implemented DSL+ successfully and a one-way ANCOVA comparing post-test expressive vocabulary scores of a sub sample of the ID numbers scored at that time indicated a significant group effect, $\mathrm{F}(1,42)=6.57, p<0.014$, $d=1.09$ (Næss et al., 2018). The researchers reported a need for additional investigation of participant characteristics that correlate with response to intervention and on features of the DSL+ design (e.g., number of sessions needed to master target words). There is also a need to include parents and to investigate training and coaching procedures that support high implementation fidelity. Single case research (SCR) designs may be particularly well-suited for investigating these questions, given that SCR typically includes detailed description of individual participant characteristics, session-by-session data analysis, and frequent direct observation of procedural fidelity (Horner et al., 2005).

\section{The Present Study}

The purpose of this study was to extend previous research on the DSL+ intervention that included Norwegian school children (Næss et al., in progress) by adapting the intervention for English-speaking children with DS and their parents. We also investigated whether teleeducation was an effective model for ongoing coaching. Our primary research question was, "Does parent-delivered, oral vocabulary intervention increase vocabulary skills of children with DS as measured by mastery tests of target words?" Our secondary aims were to: (1) determine whether our tele-education training model was associated with adequate procedural fidelity and (2) measure whether parents believed the intervention was socially valid. 


\section{Method}

\section{Participant Recruitment and Characteristics}

Eligible children were: (a) diagnosed with DS, (b) 5 to 7 years old, (c) used speech as a primary communication form, and (d) correctly responded to $30 \%$ or fewer items on a screening assessment. Children also had a parent available to implement five 20-min sessions per week for up to 15 weeks. We obtained university Institutional Review Board approval then e-mailed flyers to a regional DS association and parents of children with DS who were nominated by research staff. Seven families responded and met these criteria; subsequently, six parents gave consent and participated in screening. We used videoconference screenings during which all parents used personal devices (e.g., laptops, tablets). We administered a 30-item assessment adapted from our intervention mastery test (six words from each story; see dependent variable section). We "shared" our screen to display mastery test picture prompts, then read verbal prompts and provided $5 \mathrm{~s}$ for the child to respond (parents clarified as needed). We set a screening criterion of correct responses to $30 \%$ or fewer items to ensure that children had not previously learned a majority of words, and thus, might benefit from the intervention. Five of six children met our screening criterion; subsequently, one parent declined to participate before the intervention started due to time constraints and one participant withdrew prior to completing the study.

Characteristics of child participants (Polly, Chloe, Trent, and Della) and their parents are reported in Table 1. All children were diagnosed with DS and were between 5 and 6 years old (three female; all White and non-Hispanic). All children's standard scores on both KBIT-2 (Kaufman Brief Intelligence Test, Second Edition; Kaufman \& Kaufman, 2004; and PPVT-4 (Peabody Picture Vocabulary Test, Fourth Edition; Dunn \& Dunn, 2007) were more than two standard deviations below the mean of the normative sample (Trent omitted due to early 
withdrawal). A review of Individualized Education Programs (IEPs) indicated that all children had literacy-related goals (e.g., identify letters); however, only Della's IEP included a specific vocabulary goal. The results from a parent survey about children's early intervention services and home literacy practices (adapted from Al Otaiba et al., 2009) indicated that all children received numerous types of early intervention services, had daily access to literacy activities (e.g., being read to), and interacted with a TV or a computer/tablet on a daily basis.

Mothers were the primary interventionists in all cases; however, they reported that other parents and siblings often assisted and/or participated in small group activities. All mothers were White and non-Hispanic, their ages ranged from 33 to 48 years old, and their highest education levels ranged from some college training to graduate degrees. Two mothers reported that they were stay-at-home mothers and two had full-time occupations outside of their homes.

\section{Settings}

Parents conducted all sessions in their homes, which were located in three different cities approximately 20 to 120 miles outside of a large city in the Southern United States. Most sessions occurred at an adult- or child-sized table in a main living area of the homes (e.g., kitchen, den). We did not prescribe a specific time that parents should complete sessions; thus, session times frequently varied (e.g., time of day, day of week).

\section{Materials}

The research team provided the following materials to parents: (a) 9.7" iPads ${ }^{\circledR}$ with preloaded apps; (b) GoPro video recorders, (c) intervention manuals, (d) story scripts, (e) mastery test cards, and (f) small cards and toys for application activities. Apps included those used for DSL+ activities, uploading videos of sessions (GoPro; Box), video conferencing (Zoom), and email. Intervention manuals included task analyses for using study technology, descriptions of 
experimental procedures, step-by-step instructions for each activity, full texts for the picture books, and mastery test data forms. Parents used a picture book script on Days 1 through 3 to lead book discussions. We printed mastery test cards on half-sheets of cardstock. Table 3 includes descriptions of materials for Day 4 and 5 activities.

\section{Adapted DSL+ Intervention}

\section{Overview}

The adapted DSL+ intervention included five stories with five days of activities each. Stories were titled Hoot Is in a Hurry, Lightning the Train, Lisa is Afraid of Monsters, The Competition, and Tony Wants to Play in a Band. See Tables 2 and 3 for descriptions and examples of each activity. Sessions were 20-25 min and included two mastery tests (one from the target story; one probe). Parents completed the five days of activities, and if their child had not met the mastery criterion on our daily assessment (i.e., 10 of 12 items correct), they repeated the story and corresponding activities up to two more times. Although we asked parents to complete the group of five sessions on consecutive days, this was often difficult due to work schedules or children's other activities. We advised that parents continue the sequence as soon as possible after skipping a day.

These procedures differed from Næss et al. (in progress), who included 22 stories in their original investigation (one per week). From their set of 22 stories, we chose five stories that the researchers identified as high-interest. We chose a small set of stories to better align with a SCR design and to increase feasibility for parent implementers during this initial investigation. We also developed a mastery test that could be administered each session, rather than a pre/posttest. Because sessions occurred in homes (not schools), we omitted large group activities and instead asked parents to include at least one additional conversation partner for group activities. 


\section{Implementation Days 1 Through 3}

Sessions on Days 1-3 began with a picture book dialogue. The parent read questions from a script while the child viewed the illustrations and interactive effects within the DSL+ app (i.e., the child did not access the text). The scripts included short descriptions of the pictures and characters, concrete and abstract questions, and directions to activate interactive story effects. For example, the script for Hoot Is in a Hurry began with "Look at this! What do you think this book is about?" on the first page, which showed an illustration of an ambulance. On the next page of Hoot Is in a Hurry, the parent described the ambulance (e.g., "He has four wheels. He drives fast like lightning. He makes loud sounds. He has blue flashing lights.") while the child tapped the screen to activate an animated count of the wheels, a flashing lightning bolt, a siren sound, and flashing lights. If the child did not respond to questions after 5-10 s or responded incorrectly, parents followed the script to provide a hint. If the child did not respond again or was incorrect, the parent then modeled the correct answer. Questions increased in abstraction across the three days (e.g., from "what" to "why" questions). Book lengths ranged from 9 to 13 pages, and completing the dialogue typically took 5-8 $\mathrm{min}$.

Next, the parent and child completed eight tasks within the DSL+ app. See Table 2 for the list of tasks, the goal of each task, and examples of how the activities changed across each of the three days. Tasks included practice with the meaning of the 'main word' from each book and 10 to 11 related words. For example, the main word for Hoot Is in a Hurry was 'fast' and related words included 'speed,' 'slow,' and 'run.' During each task, the DSL+ app played audio of one instructor voice (a young female) and 20 additional voices distributed throughout activities, including samples from males, females, adults, and children. For example, during Day 1 variations tasks, the instructor voice said "Touch the images and listen to the words, " while the 
child viewed four boxes with question marks. As the child touched each box, the image flipped over and a unique voice stated the word (i.e., name of the image). The variations task for Hoot Is in a Hurry included four depictions of the word fast (a motorcycle, a cheetah, a rocket, and a train) with a different voice for each. The remaining seven tasks included a variety of instructions (e.g., listening to related words, looking at the main word in action) that increased in complexity across the three days from looking at depictions of the words, to selecting correct words from options, to producing (i.e., saying) the words while viewing the images. We asked parents to add at least one sentence of their own dialogue to each activity and provided examples in the intervention manual (e.g., during the variations task, parents might say "These are all different pictures of the word fast!"'). Parents also provided error correction and prompts as needed. Completing the eight tasks typically required fewer than $10 \mathrm{~min}$.

\section{Implementation Days 4 and 5}

Table 3 includes a list of Days 4 and 5 activities, goals, examples, and materials. Parents invited one or two additional conversation partners (e.g., siblings, other parents) to join these activities to provide an opportunity for generalization of skills to novel communication partners. On Day 4, sessions began with the parent guiding the child through telling the story to the small group while viewing the picture book on the DSL+ app. Next, the child answered four comprehension questions (e.g., What was the book about?, What was the problem?) with support and interaction from the group. Third, the group completed a practical activity with materials provided by the research team (see list of activities in Table 3). On Day 5, the parent read a longer version of the picture book (i.e., the full text) while the group viewed the pictures on the app and responded to comprehension questions. Then group completed a sequencing activity with picture cards. All sessions from Days 1 through 5 ended with two mastery tests. 


\section{Parent Training and Ongoing Coaching}

First, all participating parents watched a 13-min video that included an overview of study procedures and models of intervention tasks. Then the first author led an in-person training (1.5 to $2 \mathrm{hr}$ ) at the participant's home that followed a four-step BST format (Parsons et al., 2012).

First, she provided a verbal description of all intervention materials (e.g., manual, apps). Second, she modeled implementation of the picture book task, practice tasks, and the Story 1 mastery test. Third, the parent rehearsed at least one practice activity and three to five mastery test items while the researcher provided feedback. Fourth, the researcher coached the parent through conducting the first baseline session, including data sharing procedures.

Following the initial training, parents implemented all sessions independently and we provided ongoing support remotely. The first author video-conferenced with each parent once weekly for the first two to three weeks to answer questions, provide procedural fidelity feedback, and describe experimental decisions. For the remainder of the study, we emailed parents one to two times per week to provide feedback. We asked parents to request when they needed additional support; however, none requested this beyond the initial two to three weeks.

\section{Dependent Variable and Data Collection}

The dependent variable was the number of correct items on an oral vocabulary mastery test administered by the parents during each session. Mastery test items included words targeted within stories and practice activities (pool of 10 to 11 words per story). Words ranged from one to four syllables in length and included nouns (e.g., ambulance, game), verbs (e.g., run, yell), adjectives (e.g., quiet, slow), and adverbs (e.g., faster, slower). Although the concepts of the words' role in sentences (e.g., The music is loud.) and present/past tense (e.g., play/played) were included in DSL+, we omitted these from mastery tests due to the difficulty of picture depictions. 
Each item had one expressive and one receptive version. Expressive items included one picture prompt and a verbal statement. For example, to expressively test "loud," the parent showed a picture of a child holding his ears while standing by speakers. The parent then said, "The boy had to hold his ears at the concert. The music was just too . . The pictures were included in DSL+ practice tasks, but the verbal statements were not. Children were correct if they said the target word within $5 \mathrm{~s}$ (articulation errors were acceptable). During receptive tests, the child viewed four pictures (one correct; three distractors). Distractor pictures included one from the same story, one from a different story, and one with similar characteristics (e.g., color, shape) as the correct picture. The parent pointed to each picture and named it, then read the statement. Children could point to the corresponding picture or say the word without pointing. Each test included 12 items (six receptive, six expressive). Parents shuffled the two stacks of cards and then administered the first six items from each stack. We instructed parents to refrain from providing feedback during mastery tests.

Parents recorded scores (i.e., 0/1) on paper data forms, and then completed a secure web survey hosted at Vanderbilt University (Research Electronic Data Capture [REDCap]; Harris et al., 2009). Responses included: (1) session date, (2) session type (i.e., baseline/intervention), (3) intervention day, (4) people included if Days 4/5, (5) mastery tests completed per story, (6) mastery test scores, (7) video submission (yes/no), and (8) a box for additional information. At study conclusion, the research team reviewed original data sheets and checked data entry from surveys against the hard copies. Data entry was correct for all sessions. Parents also submitted videos of sessions on Days 1 through 3; Days 4 and 5 were omitted to facilitate inclusion of nonconsented conversation partners. Parents recorded videos with GoPro cameras that were 
positioned so that the child and all materials were visible. GoPros were connected to iPads® via WiFi; parents then uploaded videos to a researcher-owned folder within the Box app.

\section{Interobserver Agreement and Procedural Fidelity}

We collected interobserver agreement (IOA) and procedural fidelity (PF) on at least $30 \%$ of sessions for Polly, Chloe, and Della, selected semi-randomly across phases. Due to the difficulty Trent's parent had with video uploads, we observed two of 11 sessions (18.18\%). For IOA, a researcher watched the mastery test videos and independently scored each item. We then added the number of items on which our score agreed with the parent's (total possible $=12$ ), divided agreements by the sum of agreement plus disagreements, and multiplied by 100 (i.e., point-by-point IOA). Mean IOA was $95.56 \%$ (range: $75-100 \%$ ) for Polly, $96.81 \%$ (range: 83.33 100\%) for Chloe, $100 \%$ for Trent, and $94.73 \%$ (range: $83.33-100 \%$ ) for Della.

We measured PF by directly observing baseline and intervention procedures from videos (e.g., correct materials present, mastery test items completed, picture book scripts read, practice activities completed). We tallied points each time the parent completed a required component correctly and calculated PF percentages by dividing the number of correct items by the total number of required items and multiplying by 100 . Mean PF was $87.56 \%$ (range: $57.63-100 \%$ ) for Polly, 89.75\% (range: 84.48-100\%) for Chloe, 69.71\% (range: 42.12-97.29\%) for Trent, and $85.26 \%$ (range: $56.62-100 \%$ ) for Della. Scores lower than $80 \%$ occurred on six of 49 total sessions with PF data. The most common errors were omitting text from picture book scripts or dialogue during app activities (one comment/question required per activity). We also rated overall implementation quality across five indicators (e.g., frequent praise, error correction) and calculated a total quality score (range: 0-5). Polly and Della's quality ratings ranged from 4 to 5 , 
Chloe's ranged from 3 to 5, and Trent's quality was 4 on one session. The most common error was failing to provide adequate response time (i.e., 5-10 s) after asking questions.

\section{Experimental Design and Data Analysis}

We used a multiple probe (days) across behaviors design (Gast et al., 2014) to analyze the effects of parent-implemented oral vocabulary intervention on children's mastery test scores. Each of the five DSL+ stories was an experimental tier (i.e., behavior) and story order was randomized for each participant (stories did not build on each other). Parents implemented DSL+ for one to three weeks (i.e., 5 to 15 days) per story. Participants completed a minimum of three baseline sessions consisting of administration of the oral vocabulary tests only; they continued if data were unstable or had an increasing trend. Initial baseline sessions included mastery tests for Story 1 and two additional stories. Parents then began intervention. During each session, they collected mastery test data from Story 1 and one additional story (schedule provided by research team). When a participant met Story 1 mastery criterion (10 items correct), they completed three final days of intervention in the sequence during which the parent collected continuous baseline data for the next story. On some occasions, there were increasing trends in baseline; thus, parents collected additional baseline data without DSL+ implementation. Parents repeated these procedures for Stories 2 through 4 and concluded intervention with Story 5 after five days with scores of 10 or higher on the Story 5 mastery test. After a story was completed, mastery tests from that story (collected at the end of sessions) served as maintenance data.

\section{Social Validity}

We measured the social validity of DSL+ intervention goals, procedures, and results via post-intervention interviews (in-person for Polly and Chloe; on telephone for Della). Chloe's mother and father both participated in her interview and agreed on all responses. We asked 
parents to rate nine statements with a Likert-type scale $(1=$ strongly disagree $; 3=$ neutral; $5=$ strongly agree). See Table 4 for a list of all statements. We followed statements with open-ended questions. For example, after parents rated whether intervention procedures were feasible and acceptable for them to implement with their child, we asked "How would you improve the intervention?" We will describe social validity results in the next section.

\section{Results}

\section{Mastery Test Results}

See Figures 1 and 2 for graphs of participant data. Polly completed 43 total sessions and met the mastery criterion for all stories. Story 1 baseline data had a decreasing trend from 6 to 3 correct items; intervention data increased from 6 to 10 items across 9 sessions. Story 1 maintenance probes remained at intervention levels (range: 9-11). Story 2 baseline data had an overall increasing trend (range: 1-6 items correct), decreasing slightly in the final session (from 6 to 5). Story 2 intervention data increased from 6 to 11 correct items across eight sessions. Story 2 maintenance data were stable and slightly below intervention levels (range: 8-9). Story 3 baseline data ranged from 4 to 8 correct items during the Sessions 1 to 4 and were stable prior to intervention (range: 4-5). Story 3 intervention data increased from 8 to 11 correct items across seven sessions. Two Story 3 maintenance probes decreased to 9 and 6 correct items. Story 4 baseline data displayed an increasing trend (range: 4 to 7 items) that stabilized in the final three sessions (range: 6-7). Story 4 intervention data increased from 8 to 10 correct items across seven sessions; one maintenance probe (9 correct items) decreased slightly. Story 5 baseline data ranged from 0 to 3 correct items, with an increasing trend in the last four sessions. Across six days of Story 5 intervention, data increased from 2 to 10 correct items. 
Chloe completed 40 total sessions and met the mastery criterion for all stories. Story 1 baseline data ranged from 2 to 6 items correct and had a final decreasing trend. Intervention data increased from 7 to 11 correct items across 11 sessions, and maintenance data remained at intervention levels (range: 7-12). Story 2 baseline data had an increasing trend (range: 4-9 correct items), with a slight decrease in the final session (from 9 to 7 ). Chloe scored 10 on the Story 2 intervention tests across five consecutive sessions, and maintenance data remained at similar levels (range: 9-11). Story 3 baseline data increased from 2 to 8 items correct, with a slight decrease (from 8 to 7 ) in the final session. Story 3 intervention data increased from 6 to 10 correct items across eight sessions, and maintenance probes were above intervention levels (11 correct items). Story 4 baseline data ranged from 4 to 7 correct items across 10 sessions. Story 4 intervention data increased from 7 to 11 across eight sessions and remained at 10 on one maintenance probe. Story 5 baseline data increased from 4 to 10 correct items across six sessions and were stable for the final three sessions. Data across five intervention sessions increased from 9 to 11 correct items.

Trent completed 11 sessions and did not reach mastery for any story. Story 1 baseline data ranged from 0 to 1 correct item. During baseline, Trent's parent reported difficulties with her work schedule, that Trent engaged in challenging behavior during sessions (e.g., shouting, hitting, elopement), and that sharing videos was overly time-consuming due to upload speeds. We recommended that she provide small rewards (e.g., edibles) throughout sessions, praise Trent frequently, and take a break between practice tasks and mastery tests. We also reduced the video requirement to one upload per week. Across seven intervention sessions, Story 1 data increased from 1 to 6 correct items and baseline data for all other stories ranged from 0 to 6 items correct. 
However, Trent's mother reported that his challenging behaviors were unmanageable during intervention sessions and they withdrew from the study after their eleventh session.

Della completed 57 total sessions and met the mastery criterion for four stories. Story 1 baseline data had a decreased trend from 2 to 0 correct items. Across 15 sessions, Story 1 intervention data were variable but increased in level (range: 2-7 correct items; mastery criterion not met). Story 1 maintenance data were similar to intervention levels but variable. Story 2 baseline data ranged from 1 to 9 correct items; during intervention data increased in level and displayed a steep trend in the final three sessions (range: 2-12). Della scored 7 on all Story 2 maintenance tests. Story 3 baseline data ranged from 2 to 6 . Story 3 intervention data immediately increased above baseline levels, and then decreased in the final three sessions (range: 7-10). Story 3 maintenance data ranged from 8 to 10. Story 4 baseline data were low and stable with a slight increasing trend in the final four sessions (range: 0-5), intervention data displayed a steep increasing trend from 4 to 10 , and one maintenance probe decreased in level (4 correct items). Story 5 baseline data increased in level across the phase, ranging from 1 to 7. Della achieved mastery criterion for Story 5 after six sessions (range: 6-10 items correct).

\section{Social Validity Results}

See Table 4 for social validity results. We did not interview Trent's mother due to her limited experience with DSL+. Of the three parents we interviewed, all strongly agreed (rating $=$ 5) with statements about the goals of the intervention, feasibility and acceptability of training/coaching procedure, and that their child's oral vocabulary increased during DSL+ sessions. All three parents strongly agreed or agreed (rating =4) with statements regarding feasibility and acceptability of intervention (e.g., iPad® activities) and research procedures (e.g., filming sessions), and that they noticed their child using target words outside of sessions. For 
example, Polly began asking family members to "whisper", and Chloe began saying "family together" when standing with her mother and father. Della's parent shared that a few DSL+ target words (e.g., colleagues) were on the kindergarten vocabulary list her school provided at post-intervention, and she was glad Della had received exposure to those words. Polly and Chloe's parents gave a neutral rating (3) regarding their child's engagement during sessions and Della's mother indicated she was engaged (rating =4). Polly's parents noted that she was most

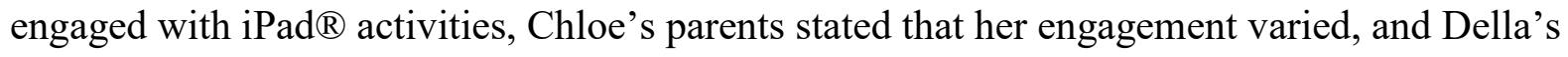
parent explained that Della became more engaged across intervention weeks. Finally, parents rated whether they used intervention strategies outside of sessions; we used these data to hypothesize whether increased scores could be due to treatment diffusion. Polly's parent did not agree (rating = 2), Chloe's parents agreed, and Della's mother responded neutrally. Polly and Chloe's parents explained that they did not purposefully implement strategies, but they frequently talked about concepts after the children initiated the conversation.

\section{Discussion}

We conducted this SCR study to investigate whether parent-implemented oral vocabulary intervention for young children with DS would result in increased scores on mastery measures of targeted vocabulary. We included four children ages 5 to 6 years old, three of whom completed the adapted DSL+ intervention (five stories, 40 to 57 sessions; Næss et al., in progress). We trained and supported parents (in all cases, mothers) via a tele-education model.

Three of the children's data demonstrated clear increases on the parent-administered mastery tests for all five stories, and two children met mastery criteria for all five stories. This suggests that participants learned to use the targeted vocabulary within the intervention and assessment context. This growth occurred within a relatively brief duration and with multi- 
syllable words that represented complex concepts (e.g., competition, relationships). These results are promising in that they add to the limited number of previous studies that investigated oral vocabulary intervention for young children with DS (see O’Toole et al., 2018; Næss et al., in progress). The DSL+ intervention includes multiple instructional components identified as effective at increasing oral vocabulary skills for children identified with or at-risk for disabilities, including direct instruction of word meanings, picture book dialogues, repetitions of stories, and exposure to target words across many contexts (Flack et al., 2010; Heidlage et al., 2019; Marulis \& Neuman, 2018; Swanson et al., 2011). Our results suggest that these strategies may also be effective for young children with DS. However, because we observed increasing data trends during baseline phases and data variability, we cannot not confidently identify a functional relation between the DSL+ intervention and mastery test scores.

Reviews of vocabulary intervention research have found limited information about parent training methods and fidelity outcomes (Heidlage et al., 2019; Roberts \& Kaiser, 2011). Thus, our findings in these areas are particularly important and encouraging. Our training and coaching procedures followed a BST format primarily delivered via tele-education. Initial training was relatively brief, including a video introduction (13-min) and one in-person session (1.5 to $2 \mathrm{hr}$ ). We then used video conferences or e-mails (15 min, once per week) for ongoing coaching. Three of four parents maintained acceptable PF with mean scores ranging from $85.26-89.75 \%$ correct steps. Furthermore, all parents collected mastery test data with a high degree of accuracy (mean IOA ranged from 94.73-100\%). These results indicate that tele-education models may be an effective way to train and support some parents to implement early intervention; this may be particularly relevant when families live a distance from trainers. Trent's parent was the exception to these results. Her fidelity decreased sharply from her first to second observation (97.29 to 
42.12\%) due to Trent's frequent challenging behavior. We provided this parent with multiple strategies to manage challenging behavior during sessions (i.e., differential reinforcement); however, the parent reported an inability to implement the recommendations and the family experienced difficulties with their internet connection. Due to these issues, it appeared that inperson coaching may have been more appropriate for their family to allow the research team to directly model the strategies with Trent. Unfortunately, we were unable to investigate these alternative methods within this study.

Three parents' responses during the post-intervention social validity interview indicated that they believed the goals and procedures of the intervention and coaching methods were feasible and acceptable. Furthermore, those parents reported that their children used the targeted vocabulary words both during and outside of sessions. Despite their positive ratings of the intervention content, parents also gave suggestions for future improvements of the administration. These included minimizing time spent on mastery tests, adapting tests to a gamelike format, and reducing video requirements (in contrast, one parent noted that videos provided accountability). These considerations are important for future SCR investigations, given that SCR is characterized by frequent data collection and fidelity checks. Readers should note that we did not ask Trent's mother to complete a social validity survey—-she indicated when she withdrew that study procedures were not feasible for her.

\section{Limitations}

There are limitations to our findings, two of which relate to our dependent measure. As we previously discussed, three participants' mastery test data displayed increasing trends during one or more baseline phases. Although we used a multiple probe design rather than a standard multiple baseline design to reduce the possibility of testing effects, these data indicate that a 
testing effect may have occurred. In other words, participants may have learned to correctly respond to some mastery test items due to repeated exposure to those items. An additional mastery test limitation is that administration included both a picture prompt and a verbal statement. Thus, we do not know which stimulus controlled children's correct responses. Participants may have associated the targeted vocabulary words with the picture(s), their parent's spoken statement, or a combination of both stimuli.

Two additional limitations relate to participants' characteristics and the use of a teleeducation model. All parents reported the same race/ethnicity and similar levels of education. Also, all of the parents had experience with the required technology (i.e., iPads $®$ ), and two of them described themselves as stay-at-home mothers (i.e., they did not have paid employment). Parents with different technology experiences and level of education may require more training and coaching than our participants, and parents who work full-time outside of their homes may have difficulty scheduling intervention sessions. Opinions about the social validity of our research procedures (e.g., filming and submitting videos) could also vary between families. Future research on this topic would benefit from inclusion of a more diverse sample than ours in order to identify such nuances. Second, we acknowledge that tele-education models may not be appropriate for families with intensive support needs (e.g., for children with challenging behavior). Although technology allowed us to enroll participants who lived up to 120 miles away, this distance prevented us from being able to provide in-person support when needed.

A final limitation relates to PF data collection. We omitted Day 4 and 5 activities because we asked families to engage with multiple conversation partners during group activities. We hypothesized that this would make study participation more feasible. Additionally, parents occasionally submitted videos with poor quality (e.g., some materials were not visible, videos cut 
short) or were unable to film sessions (e.g., camera was not charged). This affected our ability to score all procedures and to maintain a random schedule of data collection.

\section{Implications for Research and Practice}

There remain multiple avenues for future research on improving the oral vocabulary of children with DS. First, researchers should continue to investigate vocabulary measures that are appropriate for this population and for SCR. Such measures must be sensitive to change within a relatively brief time period but robust to the effects of repeated testing. Researchers must also decide how best to evoke children's use of vocabulary words. We included both pictures and spoken prompts in our mastery tests because we were concerned that pictures alone could be interpreted in multiple different ways (especially pictures of verbs [e.g., fast]) and that verbal prompts alone would be too demanding on participants' working memory (Jarrold \& Baddeley, 2001). It may be beneficial for future studies to compare multiple measures of content mastery (e.g., picture prompts, spoken prompts, or a combination) to identify those most sensitive to change.

Second, we suggest that researchers investigate methods for training parent implementers to make instructional decisions. Although we provided only brief ongoing support in this study, we did contact participants each time an instructional change was necessary (i.e., when a participant met mastery criterion). Specific to technology-based interventions like DSL+, researchers could program apps to guide participants through instructional decisions. For example, the app could include assessment materials (we used paper materials) and provide immediate feedback (i.e., continue practicing current words, introduce new words).

Third, an important implication for both research and practice relates to how end users might support parents to implement vocabulary intervention at home. Children in this study were 
5 to 6 years old, an age at which school-based education typically begins. Although parents have an integral role in the IEP process, it would likely be challenging for schools to support parents in implementing systematic interventions at home. Considering the importance of parent-child interactions in vocabulary development (O'Toole, 2018), we believe that including parents within intervention implementation is worth the effort. Nonetheless, there is a need for researchers and service providers (e.g., school) to collaboratively identify personnel with the ability (e.g., time, expertise) to support parents. This may be accomplished through collaboration with related service providers (e.g., Speech-Language Pathologists) who work in school districts or perhaps through in-home therapy providers (e.g., early interventionists). This process should be informed by an empirical investigation of methods that allow experts to release training/coaching responsibilities to end users_-BST models may be appropriate and effective.

We note that the intervention described in this study is not commercially available at the time of this writing, but we believe that parents could replicate several components. For example, a parent could identify relevant vocabulary words from school-provided lists, ask a librarian to identify books that include those vocabulary words, and then facilitate multiple exposures to that word by locating pictures/videos on the internet and in their community.

\section{Conclusion}

The findings from this study demonstrate the potential for parent-delivered interventions to support the vocabulary development of children with DS. Researchers and practitioners should continue exploring ways to effectively and efficiently support parents in providing structured vocabulary experiences to their children. Doing so will ensure that a greater number of children with DS will develop breadth and depth of vocabulary knowledge, which has the promise of providing a solid foundation to support the development of early literacy skills. 


\section{References}

Abbeduto, L., Warren, S. F., \& Conners, F. A. (2007). Language development in Down syndrome: From the prelinguistic period to the acquisition of literacy. Mental Retardation and Developmental Disabilities Research Reviews, 13, 247-261. doi:

$10.1002 / \operatorname{mrdd} .20158$

Al Otaiba, S., Lewis, S., Whalon, K., Dyrlund, A., \& McKenzie, A. (2009). Home literacy environments of young children with Down syndrome: Findings from a web-based survey. Remedial and Special Education, 30, 96-107. doi:10.1177/0741932508315050.

Baxter, R., Hulme, C., Rees, R. \& Perovic, A. (2018). Evaluating a language intervention for children with Down syndrome. Poster presented at World Down syndrome Congress, Glasgow, UK.

Chapman, R. S., Sindberg, H., Bridge, C., Gigstead, K., \& Hesketh, L. (2006). Effect of memory support and elicited production on fast mapping of new words by adolescents with Down syndrome. Journal of Speech, Language, Hearing Research, 49, 3-15. doi:

$10.1044 / 1092-4388(2006 / 001)$

Dunn, L. M. \& Dunn, D. M. (2007). Peabody Picture Vocabulary Test, Fourth Edition (PPVT4). Bloomington, MN: Pearson.

Fidler, D. J., \& Nadel, L. (2007). Education and children with Down syndrome: Neuroscience, development, and intervention. Mental Retardation and Developmental Disabilities Research Reviews, 13, 262-271. doi: 10.1002/mrdd.20166

Flack, Z. M., Field, A. P., \& Horst, J. S. (2018). The effects of shared storybook reading on word learning: A meta-analysis. Developmental Psychology, 54, 1334-1346. doi:

$10.1037 / \operatorname{dev} 0000512$ 
Gast, D. L., Lloyd, B. P., \& Ledford, J. R. (2014). Multiple baseline and multiple probe designs. In D. L. Gast \& J. R. Ledford (Eds.), Single case research methodology: Applications in special education and behavioral sciences (pp. 251-296). New York, NY: Routledge.

Harris, P. A., Taylor, R., Thielke, R., Payne, J., Gonzalez, N., Conde, J. G. (2009). Research electronic data capture (REDCap): A metadata-driven methodology and workflow process for providing translational research informatics support. J Biomed Inform, 42, 377-381. doi: 10.1016/j.jbi.2008.08.010

Heidlage, J. K., Cunningham, J. E., Kaiser, A. P., Trivette, C. M., Barton, E. E., Frey, J. R., \& Roberts, M. Y. (2019). The effects of parent-implemented language interventions on child linguistic outcomes: A meta-analysis. Early Childhood Research Quarterly, 50, 623. doi: 10.1016/j.ecresq.2018.12.006

Higbee, T. S., Aporta, A. P., Resende, A., Nogueira, M., Goyos, C., \& Pollard, J. S. (2016). Interactive computer training to teach discrete-trial instruction to undergraduates and special educators in Brazil: A replication and extension. Journal of Applied Behavior Analysis, 49, 780-793. doi: 10.1002/jaba.329

Horner, R. H., Carr, E. G., Halle, J., McGee, G., Odom, S., \& Wolery, M. (2005). The use of single-subject research to identify evidence-based practice in special education. Exceptional Children, 71, 165-179. doi: 10.1177/001440290507100203

Jordan, S., Miller, G. L., \& Riley, K. (2011). Enhancements of dialogic reading for young children with Down syndrome. Young Exceptional Children, 14, 19-30. doi: $10.1177 / 1096250611425025$ 
Jarrold, C., \& Baddeley, A. D. (2001). Short-term memory in Down syndrome: Applying the working memory model. Down Syndrome: Research and Practice, 7, 17-23. doi: 10.3104/reviews. 110

Kaufman, A. S., \& Kaufman, N. L. (2004). Kaufman Brief Intelligence Test, Second Edition (KBIT-2). Bloomington, MN: Pearson.

Kuperman, V., Stadthagen-Gonzalez, H., \& Brysbaert, M. (2012). Age-of-acquisition ratings for 30,000 English words. Behavior Research Methods, 44, 978-990. doi: 10.3758/s13428012-0210-4.

Marulis, L. M., \& Neuman, S. B. (2010). The effects of vocabulary intervention on young children's word learning: A meta-analysis. Review of Educational Research, 80, 300-335. doi: $10.3102 / 0034654310377087$

Næss, K.-A., Smith, L., Hokstad, S., \& Engevik, L. I. (2018). The effect of the Down Syndrome LanguagePlus (DSL+) intervention: A digital intervention for improving vocabulary. Paper presented at The World Down Syndrome Congress, Glasgow, UK.

Næss, K.-A., Hokstad, S., Engevik, L. I., Smith, L., \& Lervåg, A. (in progress). A block cluster randomised trial of the Down Syndrome Language Plus (DSL+): The effect of a digital vocabulary intervention programme.

Nightengale, Yoon, Wolter-Warmerdam, Daniels, \& Hickey. (2017). Understanding hearing and hearing loss in children with Down syndrome. American Journal of Audiology, 26, 301208. doi: 10.1044/2017_AJA-17-0010.

O’Toole, C., Lee, A. S. Y., Gibbon, F. E., van Bysterveldt, A. K., \& Hart, N. J. (2018). Parentmediated interventions for promoting communication and language development in 
young children with Down syndrome. Cochrane Database of Systematic Reviews, 2018(10), 1-75. doi: 10.1002/14651858.CD012089.pub2.

Parker, S. E., Mai, C. T., Canfield, M. A., Rickard, R., Wang, Y., Meyer, R.E.,...Correa, A. (2010). Updated national birth prevalence estimates for selected birth defects in the United States. Birth Defects Research Part A: Clinical and Molecular Teratology, 88, 1008-1016. doi: 10.1002/bdra.20735

Parsons, M. B., Rollyson, J. H., \& Reid, D. H. (2012). Evidence-based staff training: A guide for practitioners. Behavior Analysis in Practice, 5, 2-11. doi: 10.1007/bf03391819

Roberts, M. Y., \& Kaiser, A. P. (2011). The effectiveness of parent-implemented language interventions: A meta-analysis. American Journal of Speech-Language Pathology, 20, 180-199. doi: 10.1044/1058-0360(2011/10-0055)

Skibbe, L. E., Grimm, K. J., Stanton-Chapman, T. L., Justice, L. M., Pence, K. L., \& Bowles, R. P. (2008). Reading trajectories of children with language difficulties from preschool through fifth grade. Language, Speech, and Hearing Services in Schools, 39, 475-486.

Smith, L., Hokstad, S. \& Næss, K. (2020). Children with Down syndrome can benefit from language interventions: Results from a systematic review and meta-analysis. Journal of Communication Disorders, 85, 1-12. doi: 10.1016/j.jcomdis.2020.105992

Swanson, E. A., Wanzek, J., Petscher, Y., Vaughn, S., Heckert, Cavanaugh, C.,...Tacket, K. (2011). A synthesis of read-aloud interventions on early reading outcomes among preschool third third graders at risk for reading difficulties. Journal of Learning Disabilities, 44, 258-275. doi: 10.1177/0022219410378444. 
Van Heuven, W. J. B., Mandera, P., Keuleers, E., \& Brysbaert, M. (2014). Subtlex-UK: A new and improved word frequency database for British English. Quarterly Journal of Experimental Psychology, 67, 1176-1190. doi: 10.1080/17470218.2013.850521 
Table 1

Child and Parent Characteristics

\begin{tabular}{|c|c|c|c|c|c|c|c|c|c|}
\hline \multirow[b]{2}{*}{ Child } & \multicolumn{5}{|c|}{ Child Demographics and Assessments } & \multirow[b]{2}{*}{$\begin{array}{l}\text { Focus of IEP Literacy } \\
\text { Goals }\end{array}$} & \multicolumn{3}{|c|}{ Parent Demographics } \\
\hline & $\operatorname{Age}^{a}$ & Gender & $\begin{array}{c}\text { Race/ } \\
\text { Ethnicity }\end{array}$ & $\begin{array}{l}\text { KBIT }-2^{\mathrm{b}} \\
(90 \% \mathrm{CI})\end{array}$ & $\begin{array}{l}\text { PPVT-4 } \\
(90 \% \mathrm{CI})\end{array}$ & & Age $^{a}$ & Occupation & $\begin{array}{l}\text { Highest Ed } \\
\text { Level }\end{array}$ \\
\hline Polly & $5: 10$ & $\mathrm{~F}$ & $\mathrm{~W} ; \mathrm{N}-\mathrm{H}$ & $\begin{array}{c}54 \\
(49-63)\end{array}$ & $\begin{array}{c}64 \\
(59-70)\end{array}$ & $\begin{array}{l}\text { Answer story questions; } \\
\text { ID letter names/sounds; } \\
\text { ID pictures/objects; Read } \\
\text { sight words; Write } \\
\text { letters/name }\end{array}$ & 33 & SAHM & College degree \\
\hline Chloe & $5: 6$ & $\mathrm{~F}$ & $\mathrm{~W} ; \mathrm{N}-\mathrm{H}$ & $\begin{array}{c}56 \\
(51-65)\end{array}$ & $\begin{array}{c}34 \\
(30-42)\end{array}$ & $\begin{array}{l}\text { Match letters; Trace } \\
\text { name }\end{array}$ & 35 & $\begin{array}{l}\text { Non-profit } \\
\text { program } \\
\text { director }\end{array}$ & $\begin{array}{l}\text { Some college/ } \\
\text { vocational } \\
\text { training }\end{array}$ \\
\hline Trent & $6: 5$ & M & $\mathrm{W} ; \mathrm{N}-\mathrm{H}$ & - & - & $\begin{array}{l}\text { ID Letter sounds; Read } \\
\text { sight words }\end{array}$ & 42 & $\begin{array}{l}\text { Nurse } \\
\text { practitioner }\end{array}$ & $\begin{array}{l}\text { Graduate } \\
\text { degree }\end{array}$ \\
\hline Della & $5: 1$ & $\mathrm{~F}$ & $\mathrm{~W} ; \mathrm{N}-\mathrm{H}$ & $\begin{array}{c}50 \\
(45-59)\end{array}$ & $\begin{array}{c}38 \\
(34-46)\end{array}$ & $\begin{array}{l}\text { ID letter names; ID } \\
\text { vocabulary; Match } \\
\text { letters; Write letters }\end{array}$ & 48 & SAHM & College degree \\
\hline
\end{tabular}

Note. Demographic data were collected through online surveys. Assessments were research-administered at post-intervention. All parents reported the same race and ethnicity as their child. IEP=Individualized Education Program; SAHM=Stay at home mother; $\mathrm{W}=$ White; $\mathrm{N}-\mathrm{H}=$ Not Hispanic; ID=identification

${ }^{a}$ Child age reported in years and months; Parent age reported in years.

${ }^{b}$ Kaufman Brief Intelligence Test, Second Edition (Kaufman \& Kaufman, 2004). IQ composite reported.

cPeabody Picture Vocabulary Test, Fourth Edition (Dunn \& Dunn, 2007). Age-normed standard score reported. 
Table 2

DSL+ Activities: Days 1-3

\begin{tabular}{|c|c|c|}
\hline Activity & Goal & Activity Examples by Day \\
\hline $\begin{array}{l}\text { Picture Book } \\
\text { Dialogue }\end{array}$ & $\begin{array}{l}\text { Provide context for } \\
\text { vocab words }\end{array}$ & $\begin{array}{l}\text { 1-3. Child views picture book without text; Parent } \\
\text { uses script to tell story \& asks questions }\end{array}$ \\
\hline $\begin{array}{l}\text { Variations } \\
\text { Task }\end{array}$ & $\begin{array}{l}\text { Identify multiple } \\
\text { examples of main } \\
\text { word }\end{array}$ & $\begin{array}{l}\text { 1. Look at images and listen to words } \\
\text { 2. Select yes/no to question, "Is this a picture of...?" } \\
\text { 3. Say words from images }\end{array}$ \\
\hline $\begin{array}{l}\text { Relations } \\
\text { Task }\end{array}$ & $\begin{array}{l}\text { Identify words } \\
\text { associated with main } \\
\text { word }\end{array}$ & $\begin{array}{l}\text { 1. Look at images and hear description of word } \\
\text { relations } \\
\text { 2. Select (drag) words belonging with main word to } \\
\text { box from } 4 \text { options } \\
\text { 3. Say relation word to finish a sentence }\end{array}$ \\
\hline $\begin{array}{l}\text { Category } \\
\text { Task }\end{array}$ & $\begin{array}{l}\text { Identify category of } \\
\text { main word and other } \\
\text { words in category }\end{array}$ & $\begin{array}{l}\text { 1. Look at images and listen to words belonging to } \\
\text { category } \\
\text { 2. Select (drag) words that belong in category to box } \\
\text { 3. Say words from images }\end{array}$ \\
\hline $\begin{array}{l}\text { Role } \\
\text { Task }\end{array}$ & $\begin{array}{l}\text { Use main word in } \\
\text { context }\end{array}$ & $\begin{array}{l}\text { 1. Look video of main word in action } \\
\text { 2. Select answer to relation question after watching } \\
\text { video } \\
\text { 3. Say answer to relation question after watching } \\
\text { video }\end{array}$ \\
\hline $\begin{array}{l}\text { Articulation } \\
\text { Task }\end{array}$ & $\begin{array}{l}\text { Gain awareness of } \\
\text { main word } \\
\text { articulation }\end{array}$ & $\begin{array}{l}\text { 1. Look at video of mouth and listen to main word } \\
\text { 2. Select picture correctly saying main word } \\
\text { 3. Say main word to teach parrot (record audio) }\end{array}$ \\
\hline $\begin{array}{l}\text { First Sound } \\
\text { Task }\end{array}$ & $\begin{array}{l}\text { Gain awareness of } \\
\text { individual sounds in } \\
\text { words }\end{array}$ & $\begin{array}{l}\text { 1. Look at listen to first sound in main word } \\
\text { 2. Select picture correctly saying first sound } \\
\text { 3. Say first sound to teach parrot (record audio) }\end{array}$ \\
\hline $\begin{array}{l}\text { Singular/ } \\
\text { Plural Task }\end{array}$ & $\begin{array}{l}\text { Discriminate } \\
\text { singular/plural } \\
\text { versions of main } \\
\text { word }\end{array}$ & $\begin{array}{l}\text { 1. Look and listen to sentences with singular/plural } \\
\text { forms of main word } \\
\text { 2. Select correct picture after watching video of } \\
\text { singular/plural pronunciation } \\
\text { 3. Say singular/plural word from images }\end{array}$ \\
\hline $\begin{array}{l}\text { Present/ } \\
\text { Past Task }\end{array}$ & $\begin{array}{l}\text { Discriminate } \\
\text { present/past main and } \\
\text { related words }\end{array}$ & $\begin{array}{l}\text { 1. Look and listen to sentences of present/past } \\
\text { 2. Make a video acting out present tense of main word } \\
\text { 3. Watch video from previous day (past tense) }\end{array}$ \\
\hline
\end{tabular}

Note. All Day 1-3 activities were completed within DSL+ app. Parent and child participated in all activities. 
Table 3

DSL+ Activities: Days 4-5

\begin{tabular}{|c|c|c|c|}
\hline Activity & Goal & Task Examples & Materials \\
\hline \multicolumn{4}{|l|}{ Day 4} \\
\hline $\begin{array}{l}\text { Picture book } \\
\text { review }\end{array}$ & $\begin{array}{l}\text { Abstract thought and } \\
\text { reasoning about } \\
\text { book content }\end{array}$ & $\begin{array}{l}\text { Child tells story to group members } \\
\text { while answering abstract and } \\
\text { concrete questions }\end{array}$ & $\begin{array}{l}\text { - DSL+ app } \\
\text { - Day } 3 \text { picture book } \\
\text { script }\end{array}$ \\
\hline $\begin{array}{l}\text { Picture book } \\
\text { questions }\end{array}$ & $\begin{array}{l}\text { Increased awareness } \\
\text { of narrative structure }\end{array}$ & $\begin{array}{l}\text { Child answers summary questions } \\
\text { about main character, setting, } \\
\text { problem, character feelings, and } \\
\text { solution }\end{array}$ & $\begin{array}{l}\text { - Day } 4 \text { script with } \\
\text { questions }\end{array}$ \\
\hline $\begin{array}{l}\text { Practical } \\
\text { activity }\end{array}$ & $\begin{array}{l}\text { Extended } \\
\text { understanding of } \\
\text { words }\end{array}$ & $\begin{array}{l}\text { Group members play game that } \\
\text { applies to main word: } \\
\text { - Win: Match photos of win } \\
\text { - Friend: Discuss friendship } \\
\text { scenarios } \\
\text { - Brake: Practice driving and } \\
\text { braking } \\
\text { - Fast: Sequence pictures from } \\
\text { slow to fast } \\
\text { - Loud: Play instruments loud and } \\
\text { quiet }\end{array}$ & $\begin{array}{l}\text { - Photo cards } \\
\text { - Small racetrack and } \\
\text { toy cards } \\
\text { - Small instruments }\end{array}$ \\
\hline \multicolumn{4}{|l|}{ Day 5} \\
\hline $\begin{array}{l}\text { Read } \\
\text { picture } \\
\text { book with } \\
\text { full text }\end{array}$ & $\begin{array}{l}\text { Introduce reading } \\
\text { comprehension } \\
\text { strategies }\end{array}$ & $\begin{array}{l}\text { Group members view picture book; } \\
\text { Parent uses full text to tell story and } \\
\text { ask concrete/abstract questions }\end{array}$ & $\begin{array}{l}\text { - DSL+ app } \\
\text { - Full story text }\end{array}$ \\
\hline $\begin{array}{l}\text { Group } \\
\text { activities }\end{array}$ & $\begin{array}{l}\text { Introduce narrative } \\
\text { structure and } \\
\text { cognitive strategies }\end{array}$ & $\begin{array}{l}\text { Group members sequence story } \\
\text { events with guidance from Day } 4 \\
\text { summary questions }\end{array}$ & $\begin{array}{l}\text { - Sequencing photo } \\
\text { cards }\end{array}$ \\
\hline
\end{tabular}

Note. Activities on Days 4-5 included one or two additional conversation partners (e.g., other parent, sibling, or friend). 
Table 4

Social Validity Results by Participant

\begin{tabular}{|c|c|c|c|}
\hline Statement & Polly & Chloe & Della \\
\hline $\begin{array}{l}\text { 1. It is important to increase the number of words in my } \\
\text { child's oral vocabulary. }\end{array}$ & 5 & 5 & 5 \\
\hline $\begin{array}{l}\text { 2. It is important for me to receive training on } \\
\text { methods/interventions for increasing my child's oral } \\
\text { vocabulary. }\end{array}$ & 5 & 5 & 5 \\
\hline $\begin{array}{l}\text { 3. The DSL+ intervention procedures (e.g., stories, iPad } \\
\text { activities, group activities) were feasible and acceptable } \\
\text { for me to implement with my child. }\end{array}$ & 5 & 4 & 4 \\
\hline $\begin{array}{l}\text { 4. The DSL+ parent training and coaching procedures (e.g., } \\
\text { in-person visit, videoconferences, e-mails) were feasible } \\
\text { and acceptable for me. }\end{array}$ & 5 & 5 & 5 \\
\hline $\begin{array}{l}\text { 5. The DSL+ research procedures (e.g., mastery tests, } \\
\text { filming sessions, submitting videos, submitting surveys) } \\
\text { were feasible and acceptable for me. }\end{array}$ & 4 & 4 & 4 \\
\hline $\begin{array}{l}\text { 6. My child was engaged during DSL+ intervention } \\
\text { sessions. }\end{array}$ & 3 & 3 & 4 \\
\hline $\begin{array}{l}\text { 7. I noticed growth in my child's oral vocabulary during } \\
\text { DSL+ sessions. }\end{array}$ & 5 & 5 & 5 \\
\hline $\begin{array}{l}\text { 8. I noticed my child using the vocabulary words he/she } \\
\text { learned outside of DSL+ sessions. }\end{array}$ & 5 & 5 & 4 \\
\hline $\begin{array}{l}\text { 9. I used intervention strategies (e.g., dialogic reading } \\
\text { questions) outside of DSL+ sessions. }\end{array}$ & 2 & 4 & 3 \\
\hline
\end{tabular}

Note. Parents rated statement on Likert-type scale $(1=$ strongly disagree; $3=$ neutral; $5=$ strongly agree). Trent's mother did not complete a social validity survey. 
Figure 1

Polly and Chloe's Mastery Test Performance

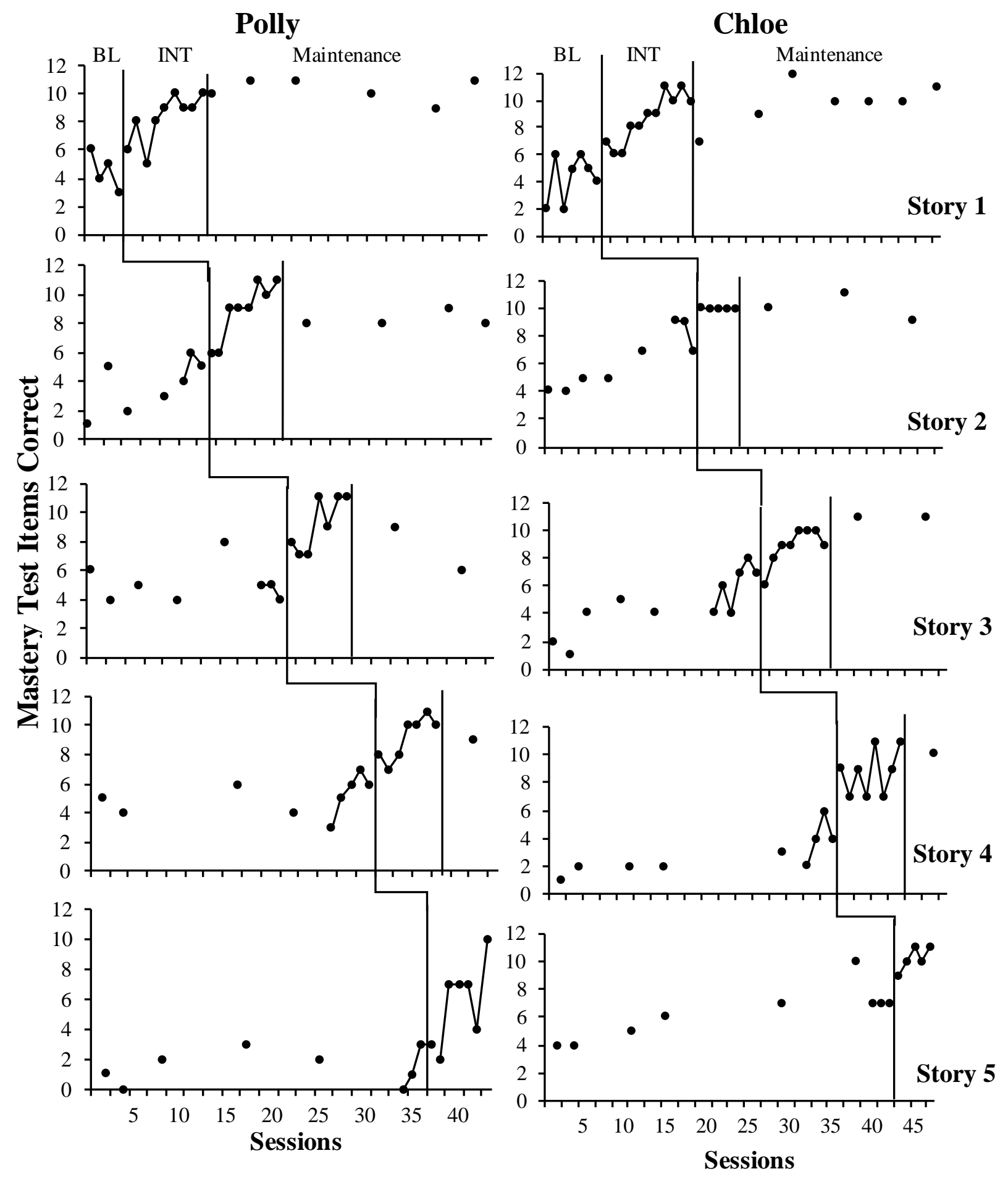

Note. $\mathrm{BL}=$ baseline; $\mathrm{INT}=$ intervention 
Figure 2

Trent and Della's Mastery Test Performance

Trent
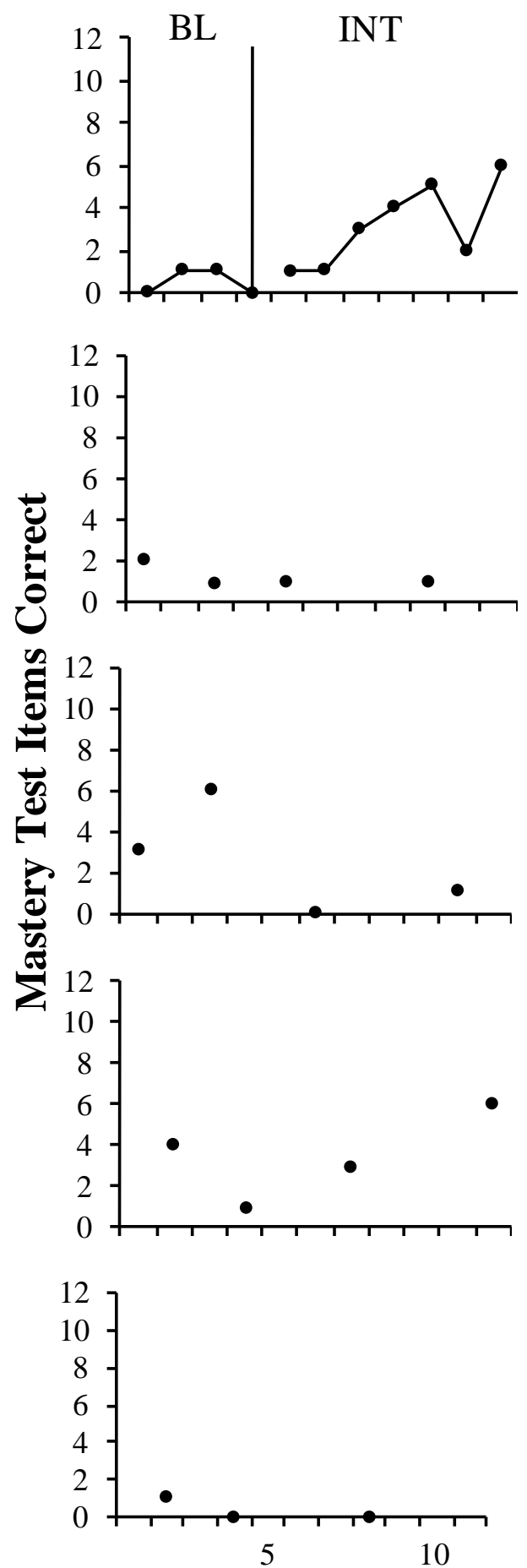

Della
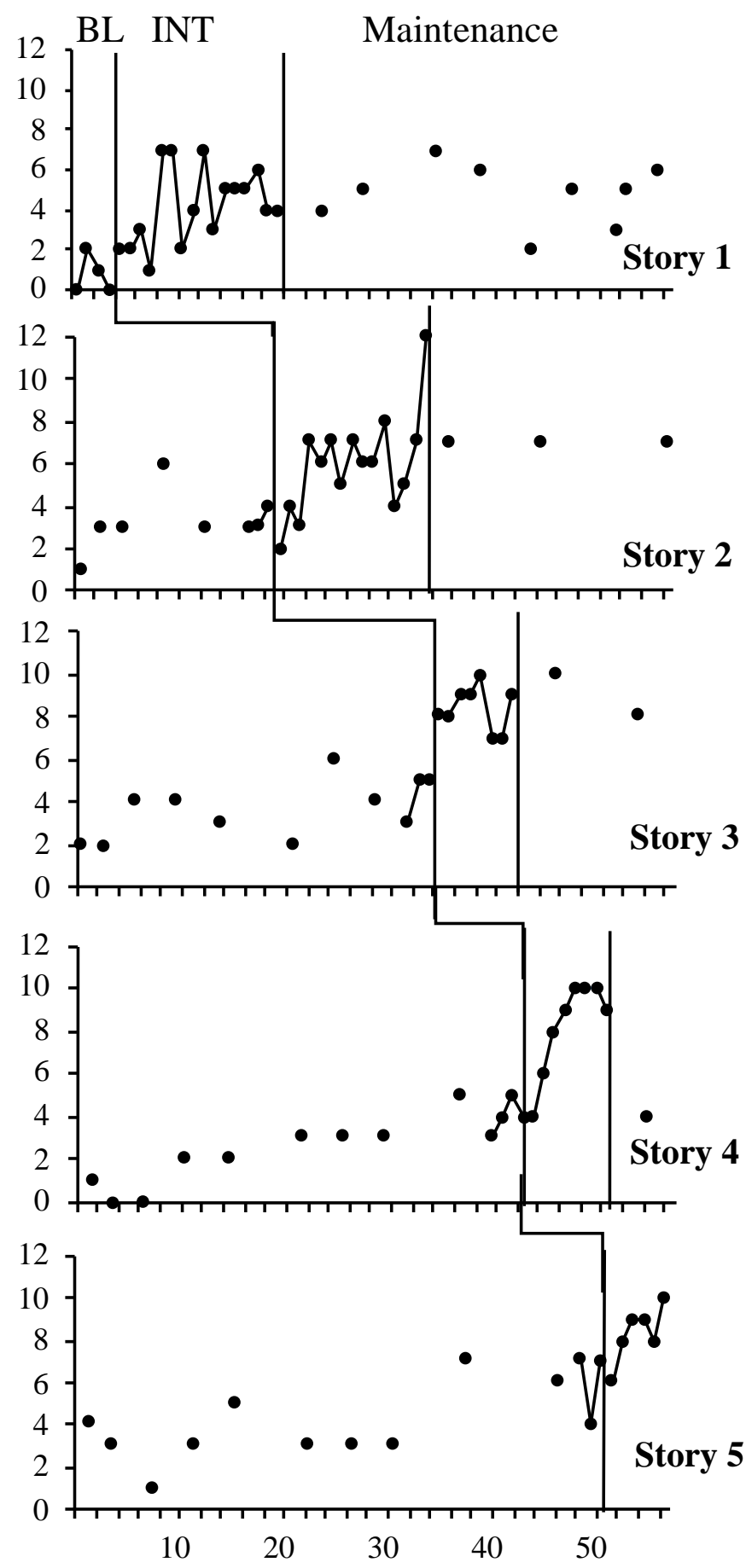

Note. $\mathrm{BL}=$ baseline $; \mathrm{INT}=$ intervention 


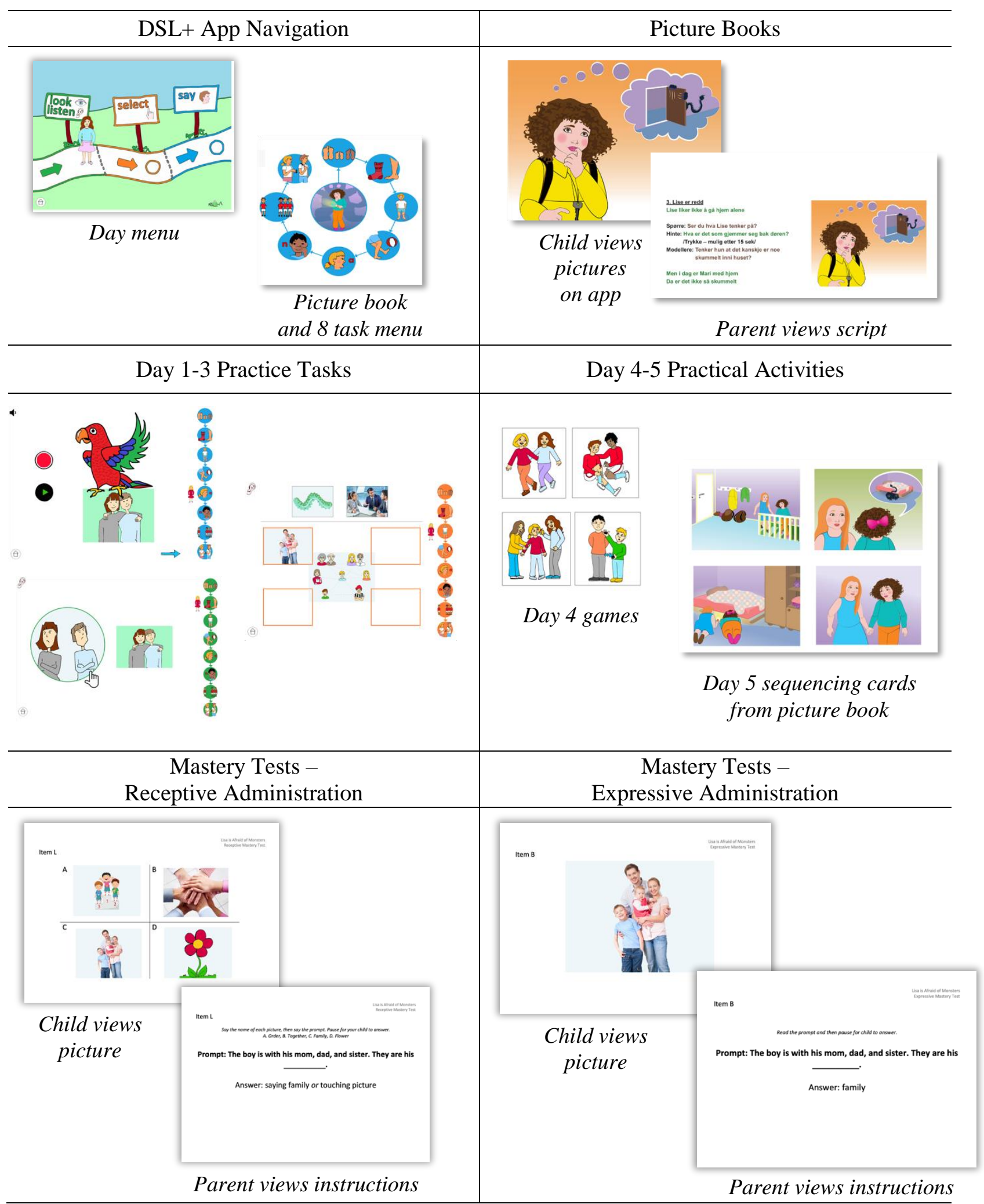

Note: Different visual lay out (drawings, pictures, cartoon characters etc. illustrating the same word) are used throughout the program in order to train generalization. Illustration of

- DSL+ App navigation by Mariell Laastad, and Elisabeth Smith; 
- $\quad$ Picture book Lise is afraid of monsters and script by Beate Erikke Johansen;

- Day 1-3 Practice Tasks family and colleagues are from Colourbox, friends and enemies are by Gunn Berit Langeland, other visual material Marielle Laastad/Elisabeth Smith;

- Day 4-5 Practical Activities games is by Marielle Laastad/Elisabeth Smith, sequencing cards is by Beate Erikke Johansen;

- Mastery test Receptive Administration win is from Shutterstock.com, hands (to be together) and family are from Colourbox, flower is by Marielle Laastad/Elisabeth Smith;

- Mastery test Expressive Administration family is from Colourbox. 